\title{
Single-incision port-site herniation: meta-analysis vs. nationwide cohort study
}

\author{
K. Bury ${ }^{1} \cdot$ M. Pawlak ${ }^{1}$ - M. Śmietański ${ }^{2}$ F. Muysoms ${ }^{3}$
}

Received: 9 May 2015/Accepted: 12 June 2015/Published online: 30 June 2015

(c) The Author(s) 2015. This article is published with open access at Springerlink.com

Single-incision laparoscopic surgery is gaining popularity [1-3]. Recently, two papers on single-incision port-site hernia have been published: first, a nationwide prospective, matched cohort study from the Danish database with 552 patients selected to match pre-defined inclusion criteria with 4 years period follow-up [4]; second, the meta-analysis conducted by the Bohnam Group, European Hernia Society Guidelines Development Group for Guidelines on the closure of abdominal wall incisions, where 19 randomized trials encompassing 1705 patients were included with a wide range of follow-up from 1 month to 1 year $[5,6]$.

The presented results in both studies were divergent in terms of the number of incidence of port-site herniation. The Danish study presented no difference in the cumulated incidences of port-site hernias with $4 \%$ in the single-incision group and $6 \%$ for classic laparoscopy $(p=0.560)$. On the other hand, the meta-analysis revealed statistically significant difference in the incidence of trocar-site hernia occurring in $2.2 \%$ of patients in the single-incision group and in $0.7 \%$ of patients in the conventional laparoscopic surgery group (odds ratio $2.26,95 \%$ confidence interval $1.00-5.08, p=0.05$ ).

Both studies have a clear and transparent description of methodology and flow diagrams for the patients' inclusion,

K. Bury

kbury@gumed.edu.pl

1 Department Cardiac and Vascular Surgery, Medical University of Gdansk, Debinki 7, 80-211 Gdańsk, Poland

2 II Department of Radiology, Medical University of Gdańsk, Gdańsk, Poland

3 Department of Surgery, AZ Maria Middelares, Ghent, Belgium so that the obtained results are acceptable. Therefore, it raises questions on what kind of studies should be trusted more and on what results should we rely when creating international guidelines.

When taking into consideration only the level of evidence according to the hierarchical classification system, the meta-analysis is the most significant. Nevertheless, data derived from National Patient Registers, especially with long-term follow-up (the median observation time was 48 months in the Danish study) and with outstanding methodological approach (every patient with single-incision laparoscopic cholecystectomy was matched with two patients with conventional laparoscopic cholecystectomy performed with respect to strict inclusion criteria to ensure the homogeneity of the two groups) give us an overview of the examined issue in terms of not only included patients, but in addition allows to account different surgeons and hospitals.

At times when we have overflowing information with new meta-analyses published every month, we need to have clear criteria for assessing the current literature. The available grading systems are not ideal and furthermore create confusion not only for the average reader, but also for the guidelines creators [7]. On the basis of this example, we would like to point out that even small differences in the results in conjunction with the grading of the level of evidence result in large differences in the lesson learned. On one hand, we should agree with the opinion of the Bonham Group that in the light of current evidence, it is necessary to alert the surgical community regarding the potential higher risk of incisional hernia associated with single-incision laparoscopic surgery involving entry into the peritoneal cavity through an umbilical incision [5].

On the other hand, there is no true long-term advantage of the selection of the operating method (single incision vs. 
classic laparoscopy), and avoiding trocar site hernia lays in proper abdominal wall closure, which we should always be aware of.

Conflict of interest K.B. declares no conflict of interest, M.P. declares no conflict of interest, M.Ś. declares no conflict of interest, F.M. declares no conflict of interest.

Open Access This article is distributed under the terms of the Creative Commons Attribution-NonCommercial 4.0 International License (http://creativecommons.org/licenses/by-nc/4.0/), which permits any noncommercial use, distribution, and reproduction in any medium, provided you give appropriate credit to the original author(s) and the source, provide a link to the Creative Commons license, and indicate if changes were made.

\section{References}

1. Arezzo A, Scozzari G, Famiglietti F et al (2013) Is single-incision laparoscopic cholecystectomy safe? Results of a systematic review and meta-analysis. Surg Endosc 27:2293-2304. doi:10.1007/ s00464-012-2763-9
2. Vettoretto N, Cirocchi R, Randolph J, Morino M (2014) Acute appendicitis can be treated with single incision laparoscopy: a systematic review of randomized controlled trials. Color Dis n/an/a. doi:10.1111/codi.12839

3. Lee DY, Rehmani SS, Guend H et al (2013) The incidence of trocar-site hernia in minimally invasive bariatric surgery: a comparison of multi versus single-port laparoscopy. Surg Endosc Other Interv Tech 27:1287-1291. doi:10.1007/s00464-012-2597-5

4. Christoffersen MW, Brandt E, Oehlenschläger J et al (2015) No difference in incidence of port-site hernia and chronic pain after single-incision laparoscopic cholecystectomy versus conventional laparoscopic cholecystectomy: a nationwide prospective, matched cohort study. Surg Endosc. doi:10.1007/s00464-015-4066-4

5. Antoniou SA, Morales-Conde S, Antoniou GA et al (2015) Singleincision laparoscopic surgery through the umbilicus is associated with a higher incidence of trocar-site hernia than conventional laparoscopy: a meta-analysis of randomized controlled trials. Hernia. doi:10.1007/s10029-015-1371-8

6. Muysoms FE, Antoniou SA, Bury K et al (2015) European Hernia Society guidelines on the closure of abdominal wall incisions. Hernia 19:1-24. doi:10.1007/s10029-014-1342-5

7. Goldet G, Howick J (2013) Understanding GRADE: an introduction. J Evid Based Med 6:50-54. doi:10.1111/jebm.12018 